\title{
ОЦЕНКА СОСТОЯНИЯ ПРИПОСЕЛКОВЫХ КЕДРОВНИКОВ ТОМСКОЙ ОБЛАСТИ С ИСПОЛЬЗОВАНИЕМ ДАННЫХ ДИСТАНЦИОННОГО ЗОНДИРОВАНИЯ ЗЕМЛИ
}

\author{
Пасько Ольга Анатольевна',
} oap@tpu.ru

\section{Токарева Ольга Сергеевна',} ost@tpu.ru

\author{
Алшаиби Ахмед Джамал Абдулрахман ${ }^{12}$, \\ ahmedalshaiby88@gmail.com

\section{Черникова Татьяна Юрьевна',} \\ chernikova@green.tsu.ru

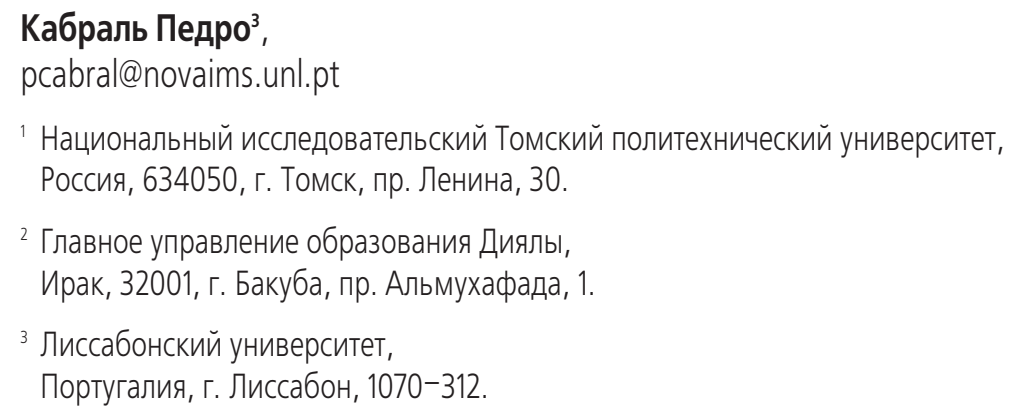

Актуальность исследования обусловлена необходимостью получения объективной, в Т. ч. ретроспективной, информации о состоянии ценных лесных массивов, являющихся ботаническими памятниками природы, для организации их охраны от пожаров, болезней и вредителей.

Цель: мониторинг состояния припоселковых кедровников на примере Томской области с использованием методов наземного обследования и данных дистанционного зондирования Земли.

Объекты: 13 припоселковых кедровников, которые являются особо охраняемыми территориями, относятся к лесничествам филиала ОГУ «Томское управление лесами» Томской области и расположены на землях лесного фонда.

Методы: тематическое картирование территории; расчет показателя количества фотосинтетически активной биомассы NDVI (Normalize Difference Vegetation Index) по космическим снимкам среднего пространственного разрешения (30 м) со спутников Landsat 5 (камера TM), 7 (камера ETM+) и 8 (камера OLI), полученных в период с 2002 по 2015 гг. из архива Геологической службы США с использованием интернет-сервиса Earth Explorer; пространственный анализ данных с использованием геоинформационных технологий; статистическая обработка полученных результатов путем проведения корреляционного и регрессионного анализа.

Результаты. Дана комплексная оценка состояния 13-ти припоселковых кедровников; проведен анализ динамики значений NDVI в период с 2002 по 2017 гг. и установлены основные причины (незаконные вырубки, ветровалы, пожары и распространение вредителей); проведена группировка кедровников по их состоянию; установлены максимальные значения NDVI для Богашовского и Белоусовского кедровников, минимальные - для Аксеновского, Плотниковского и Протопоповского кедровников; показаны положительные корреляции между значениями NDVI и состоянием деревьев: высокая корреляция - с индексом жизненного состояния, и средняя - со средневзвешенной категорией состояния деревьев в древостое; достоверные корреляционные связи значений NDVI кедровников с количеством осадков и суммой температур не обнаружены (за исключением Аксеновского кедровника, характеризуемого как «сильно ослабленный»); предложенные подходы применимы к оценке любых кедровников.

\section{Ключевые слова:}

Кедровники, мониторинг, состояние, оценка, наземное обследование, данные дистанционного зондирования, NDVI.

\section{Введение}

Оценка состояния лесных массивов актуальна для многих регионов планеты [1], поскольку оно влияет на биоразнообразие, водный режим экосистем, депонирование диоксида углерода, климат, а также на эффективность лесохозяйственного и лесозаготовительного производства [2]. Соответствующая информация необходима для решения целого ряда научных и прикладных задач, в т. ч. по планированию охраны и защиты лесов, лесо- пользованию и лесовосстановлению, а также по принятию адекватных и оперативных управленческих решений. В последние годы все большее применение в оценке лесных ресурсов находят данные дистанционного зондирования Земли (ДЗЗ) из космоса, позволяющие:

а) проводить мониторинг и инвентаризацию земель лесного фонда [3], в т. ч. осуществлять слежение за их санитарным и лесопатологическим состоянием; 
б) определять устойчивость экосистем к экстремальным воздействиям [4];

в) сравнивать состояние больших массивов леса [4] в разные периоды времени - от практически реального до ретроспективного [5], и выявлять многолетнюю динамику их состояния в любой точке планеты, в т. ч. на труднодоступных территориях [6];

г) повышать точность определения площади усыхающих древостоев;

д) эффективно планировать наземное обследование [7].

В научных исследованиях широко используют данные, получаемые со спутников природно-ресурсного назначения [8-10]. Съемочная аппаратура, установленная на этих спутниках, позволяет получать мультиспектральные снимки в различных диапазонах электромагнитного спектра. Для решения конкретных задач выбираются оптимальные комбинации каналов [11], наилучшим образом соответствующие специфике объектов исследований. Эффективными инструментами для обработки и анализа полученных данных служат геоинформационные системы и технологии $[12,13]$.

С помощью ДЗ3 ведется оценка изменения состояния лесных массивов под влиянием факторов природной и антропогенной природы, таких как изменение климата [14-16], ураганы [17], засухи, болезни и вредители [18], пожары [19-21], лесозаготовки и незаконные рубки леса [22]. $K$ примеру, установлена деградация лесных массивов под действием урбанизации на юге Мексики [23], климатических изменений в Центральной Европе [24], Юго-Восточной Азии [25] и Канаде [25, 26]. Изучено влияние особенностей ландшафтов, породного состава, климата, свойств почвы и лесной подстил- ки на возникновение и распространение лесных пожаров [24] в Швеции [27], России [28, 29] и горных массивах тропического пояса [30]. Пожары, болезни и вредители не только ведут к деградации леса, но и негативно влияют на коммерческие прогнозы объемов лесозаготовок [30-32]. В США космические снимки используют для наблюдений и прогнозов последствий неблагоприятных факторов на миллионах гектарах лесных массивов и для оценки нанесенного ущерба $[1,33]$. В Мьянме в ряде регионов на 10 лет отменены все лесозаготовительные операции, контроль которых ведется с помощью ДЗ3 [34].

Мониторинг состояния лесных массивов особенно актуален для России, около половины территории которой занято лесами, а содержание древесины превышает 20 \% мирового запаса. Низкий уровень охраны лесов от пожаров, болезней и вредителей ведет к ежегодному сокращению площади лесов на 2 млн га, поэтому в России особое внимание уделяется учету и оценке состояния лесных ресурсов [35, 36] и способности к лесовозобновлению [37, 38] хозяйственно ценных древесных пород [39], в том числе сосны кедровой сибирской (кедр сибирский) [40].

По площади кедровых лесов Томская область занимает третье место в Сибирском федеральном округе (3,6 млн га из 19,3 млн га лесных массивов. Карта-схема, показывающая расположение кедровников, приведена на рис. $1, \mathrm{~A}$, внешний вид одного из них - на рис. 1, Б. Площадь потенциальных кедровников в Томской области достигает 2 млн га. Преобладают приспевающие и средневозрастные кедровники (39 и 41 \% площади соответственно), спелые и перестойные кедровники занимают площадь в 14 \% от общей площади кедровых лесов.

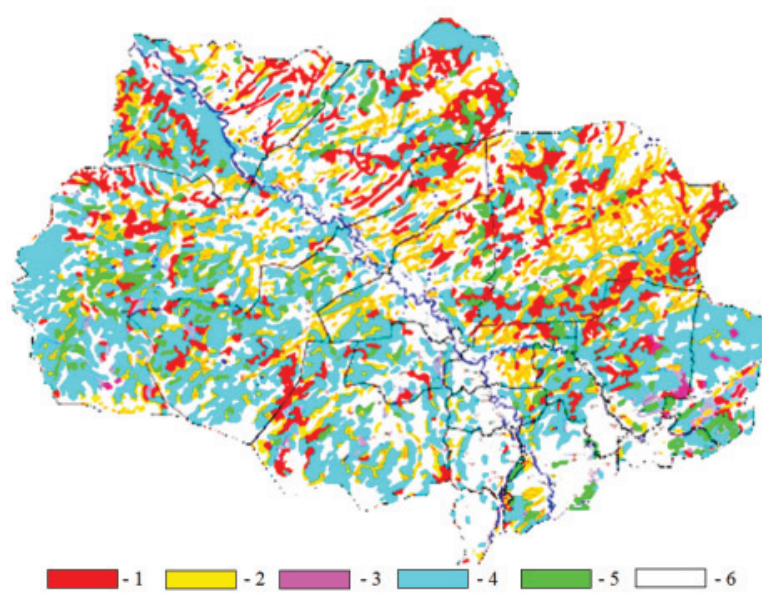

A

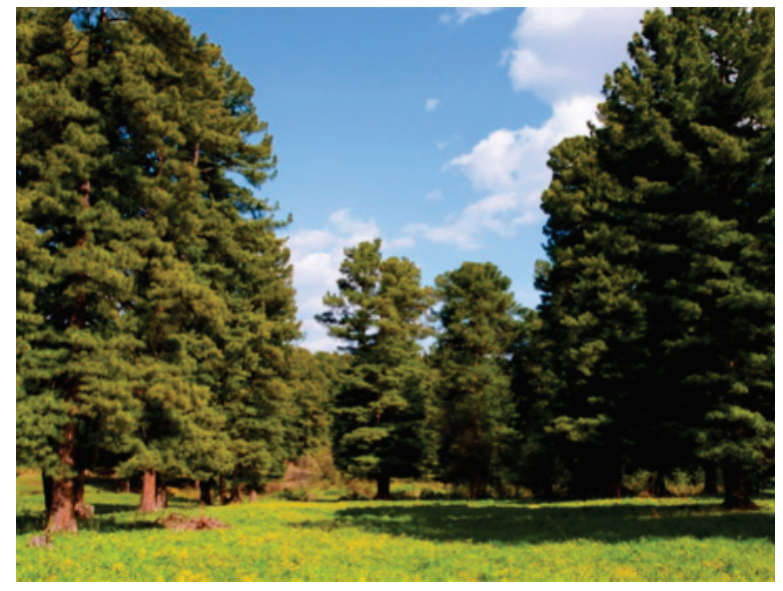

Б

Pис. 1. Расположение кедровников на территории Томской области по данныл ОГУ «Облколприрода» (А): 1 - кедровый лес, 2 - сосновый лес, 3-слешанный темнохвойный лес, 4-слешанный лес с преобладанием мелколиственных пород, 5 - мелколиственный лес, 6 - незалесенные территории; и внешний вид Богашовского кедровника (Б)

Fig. 1. Location of cedar forests in the Tomsk region according to OGU «Oblkompriroda» (A): 1 - cedar forest, 2 - pine forest, 3 - mixed dark coniferous forest, 4 - mixed forest with predominance of small-leaved species, 5 - small-leaved forest, 6 - non-forested areas; and appearance of Bogashouskiy cedar forest $(B)$ 
Кедры характеризуются декоративностью, фитонцидностью и долговечностью (500-800 лет); древесина - прочностью и легкостью. Она используется в качестве строительного и поделочного материала. Хвоя, живица и орехи являются источником ценных природных соединений для получения лекарств, скипидара, канифоли и кондитерских изделий [41].

Среди популяций сосны сибирской важное научное [42], экономическое, экологическое [43], социальное и духовное [44] значение имеют кедровые насаждения припоселкового типа [45], максимально сохранившиеся на юге Томской области. Многие из них являются особо охраняемыми объектами и имеют статус памятников природы Томской области. Кедровники чувствительны к состоянию окружающей среды и часто используются в качестве биоиндикаторов [46]. Негативные воздействия природного и антропогенного характера вызывают изменения породного состава деревьев, их возраста, высоты, диаметра, класса бонитета и т. д. [43].

В кедровниках Томской области доля ослабленных деревьев составляет в среднем 30,6 \% . В ряде из них отмечено сокращение лесопокрытой площади, к примеру, в Протопоповском - на 70 \% из-за отчуждения ценных лесных земель под жилищное и производственное строительство вблизи населенных пунктов, неконтролируемого сбора урожая орехов, проведения превентивных выборочных санитарных рубок и т. д. [43].

Несмотря на относительную близость к областному центру и сравнительно небольшие площади кедровников, их сплошное и синхронное изучение только методами наземного обследования не представляется возможным. Лесопатологическое обследование, основанное на оценке дефолиации или дехромации крон репрезентативной выборки отдельных деревьев и определение интегральных характеристик состояния насаждений требует значительных финансовых, временных и трудовых ресурсов. Его регулярное проведение для оценки состояния даже ценных кедровников практически нереализуемо. В то же время применение методов Д33 позволяет своевременно выявлять локализацию проблемных участков, их площади, оценивать динамику состояния растительного покрова и минимизировать расходы на их обнаружение.

Целью данного исследования является количественная и качественная оценки изменения состояния припоселковых кедровников Томской области за 15-летний период с 2002 по 2017 гг. с использованием данных ДЗЗ.

\section{Объекты и методы исследований}

Объектами исследования являются припоселковые кедровники, которые относятся к лесничествам филиала ОГУ «Томское управление лесами» Томской области. Они расположены между 56-61 с. ш. и $75-89^{\circ}$ в. д. на землях лесного фонда и являются ботаническими памятниками природы. Опи- сание кедровников приведено по паспортам, имеющимся в ОГБУ «Облкомприрода» (по состоянию на 01.01.2018 г.), по «Атласу особо охраняемых природных территорий Томской области» [47], а также по данным наземных обследований [42-45] (табл. 1). Расположение каждого кедровника привязано к конкретному населенному пункту или лесничеству, лесному кварталу (части лесного массива, отграниченной на местности, являющейся постоянной учетной и хозяйственной единицей) или выделу (участку, однородному по почвенногрунтовым условиям и произрастающей на нем растительности) в соответствии с картами земель лесного фонда Томской области.

Таблица 1. Территориальная характеристика припоселковых кедровников, выбранных в качестве объектов исследования

Table 1. Territorial characteristics of the cedar forests, chosen as objects of study

\begin{tabular}{|c|c|}
\hline Название/Name & Расположение/Location \\
\hline $\begin{array}{l}\text { Нижне-Сеченовский } \\
\text { Nizhne-Sechenovskiy }\end{array}$ & $\begin{array}{l}\text { квартал (кв.) 139, за исключением } 17 \text { выде- } \\
\text { ла, Темерчинского участкового лесничества } \\
\text { Тимирязевского лесничества } \\
139 \text { quarter (sq), with the exception of allot- } \\
\text { ment 17, Temerinska district forestry } \\
\text { Timiryazev forestry }\end{array}$ \\
\hline $\begin{array}{l}\text { Трубачевский } \\
\text { Trubchevskiy }\end{array}$ & $\begin{array}{l}\text { в границах Томского района у пос. Трубачево } \\
\text { within the boundaries of Tomsk region near the } \\
\text { village Trubachevo }\end{array}$ \\
\hline $\begin{array}{l}\text { Петровский } \\
\text { Petrovskiy }\end{array}$ & $\begin{array}{l}\text { в границах Томского района у д. Петрово } \\
\text { within the borders of the Tomsk region near } \\
\text { the village Petrovo }\end{array}$ \\
\hline \multicolumn{2}{|c|}{$\begin{array}{c}\text { Богашевское участковое лесничество Томского лесничества } \\
\text { Bogashovskoe precinct forestry of Tomsk forestry }\end{array}$} \\
\hline $\begin{array}{l}\text { Aксеновский } \\
\text { Aksenovskiy }\end{array}$ & $\begin{array}{l}\text { кв. } 46, \text { выделы } 4 \text { и } 5 \text { и кв. } 48, \text { выделы } 2,4,6 \\
46 \text { sq., areas } 4 \text { and } 5 \text { and } 48 \text { sq., areas } 2,4,6\end{array}$ \\
\hline $\begin{array}{l}\text { Белоусовский } \\
\text { Belousovskiy }\end{array}$ & $\begin{array}{l}\text { кв. } 50 \text {, за исключением } 13 \text { выдела, и кв. } 51 \text {, } \\
\text { за исключением выделов } 7,8,14,15 \text { и } 17 \\
50 \text { sq, with the exception of areas } 13 \text {, and } \\
51 \text { sq., with the exception of areas } 7,8,14 \text {, } \\
15 \text { and } 17\end{array}$ \\
\hline $\begin{array}{l}\text { Богашевский } \\
\text { Bogashovskiy }\end{array}$ & $\begin{array}{l}\text { кв. } 33, \text { выделы } 7,12,21,32,35 \text { и участки } 4, \\
6,10,17,18,20,34 \text { выделов } \\
33 \text { sq., cells } 7,12,21,32,35 \text { and sections } 4,6, \\
10,17,18,20,34 \text { sites }\end{array}$ \\
\hline $\begin{array}{l}\text { Вороновский } \\
\text { Voronovskiy }\end{array}$ & $\begin{array}{l}\text { кв. } 39-41 \text { урочища «Богашевское» } \\
39-41 \text { sq. of tract «Bogashevskoe» }\end{array}$ \\
\hline $\begin{array}{l}\text { Лоскутовский } \\
\text { Loskutovskiy }\end{array}$ & $\begin{array}{l}\text { кв. } 32, \text { за исключением выделов } 6,11,23,32 \\
32 \text { sq., with the exception of sites } 6,11,23,32\end{array}$ \\
\hline $\begin{array}{c}\text { Лесной парк у села Яр } \\
\text { Forest Park near the } \\
\text { village Yar }\end{array}$ & $\begin{array}{l}\text { в окрестностях с. Яр } \\
\text { in the vicinity of the village Yar }\end{array}$ \\
\hline $\begin{array}{l}\text { Магадаевский } \\
\text { Magadaevskiy }\end{array}$ & $\begin{array}{l}\text { кв. } 31 \text {, за исключением } 2,10 \text { выделов } \\
31 \text { sq., except 2, } 10 \text { areas }\end{array}$ \\
\hline $\begin{array}{l}\text { Петуховский } \\
\text { Petukhovskiy }\end{array}$ & $\begin{array}{l}\text { кв. } 42 \text {, за исключением выдела } 12 \text {, кв. } 43,44 \text {, } \\
\text { за исключением выдела } 3 \text { и кв. } 45 \\
42 \text { sq., with the exception of allotment } 12 \text {, area } \\
43,44 \text {, with the exception of part } 3 \text {, and } 45 \text { sq. }\end{array}$ \\
\hline $\begin{array}{l}\text { Плотниковский } \\
\text { Plotnikovskiy }\end{array}$ & $\begin{array}{l}\text { кв. } 27-30 \\
27-30 \text { sq. }\end{array}$ \\
\hline $\begin{array}{c}\text { Протопоповский } \\
\text { Protopopovskiy }\end{array}$ & $\begin{array}{l}\text { кв. } 25, \text { за исключением выделов } 11 \text { и } 12 \text { и кв. } \\
26, \text { за исключением выделов } 14 \text { и } 15 \\
25 \text { sq., with the exception of sites } 11 \text { and } \\
12 \text { and } 26 \text { sq., with the exception of areas } 14 \\
\text { and } 15\end{array}$ \\
\hline
\end{tabular}


Породный состав и состояние изученных кедровников различны. В 2002 г. к наиболее ослабленным относились Аксеновский и Лоскутовский, к ослабленным - Белоусовский и Лучаново-Ипатовский, к здоровым - Богашевский и Магадаевский. Самыми старыми кедровниками являются Лоскутовский (127 лет), Аксеновский (126 лет), Протопоповский (122 года) и Петуховский (121 год), самым молодым - Магадаевский. Максимальная высота деревьев отмечена в Аксеновском, Вороновском, Петуховском и Протопоповском кедровниках (23,2-23,9 м), минимальная - в Магадаевском кедровнике, а также на отдельных участках Аксеновского и Лоскутовского кедровников (15,5-19,0 м). К высокобонитетным отнесены Вороновский, Лучаново-Ипатовский, часть Петуховского и Богашовского кедровников; к среднебонитетным - Аксеновский, часть Богашовского, Лоскутовского и Плотниковского кедровников. Наибольшие запасы древесины установлены в Протопоповском и частично в Аксеновском кедровнике (338-393 м³ $/$ га), минимальные - на отдельных участках Аксеновского и Лоскутовского кедровников (170-190 м³ $/$ га).

По представленным в паспортах схемам кедровников, датированным 2008 и 2009 гг. и содержащим их границы и координаты поворотных точек, построен тематический векторный слой цифровой карты территории, в котором каждый кедровник представлен в виде полигона. Географическая привязка схем и оцифровка границ кедровников выполнена с использованием программного обеспечения ERDAS IMAGINE 9.2 [48]. Фрагменты итоговой карты, показывающие расположение кедровников при их наложении на космический снимок, приведены на рис. 2. Итоговая карта представлена в системе координат картографической проекции UTM (зона 43, WGS84), используемой для космических снимков со спутников Landsat на данной территории.
Для оценки состояния припоселковых кедровников использован вегетационный индекс NDVI (Normalized Difference Vegetation Index), являющийся показателем количества фотосинтетически активной биомассы. NDVI рассчитывается по данным космических снимков и имеет лучшую чувствительность к изменениям растительного покрова [49]. Его расчет базируется на двух стабильных участках спектральной кривой отражения сосудистых растений. Первый участок связан с максимумом поглощения хлорофиллом в красной области (0,6-0,7 мкм), второй - с максимумом отражения клеточными структурами листа в инфракрасной области (0,7-1,0 мкм). Значения NDVI вычислены по формуле:

$$
N D V I=\frac{\rho_{\text {nir }}-\rho_{\text {red }}}{\rho_{\text {nir }}+\rho_{\text {red }}},
$$

где $\rho_{\text {nir }}$ - значения коэффициента спектральной яркости пикселя в ближнем инфракрасном диапазоне; $\rho_{\text {red }}$ - в красном диапазоне электромагнитного спектра [49].

Значения NDVI рассчитаны по космическим снимкам среднего пространственного разрешения (30 м) со спутников Landsat 5 (камера TM), Landsat 7 (камера ETM+) и Landsat 8 (камера OLI), которые широко используются для построения временных рядов данных при мониторинге состояния лесов [23-25, 50]. Исходные снимки уровня обработки L1T получены из архива Геологической службы США с использованием интернет-сервиса Earth Explorer [51], который предоставляет возможность задания границ исследуемой области для подбора снимков, указания координат снимков с использованием координатной системы WRS2, даты и/или временного интервала съемки, процента покрытия облачностью и т. д. Перечень использованных в работе снимков приведен в табл. 2. Их выбор обусловлен отсутствием облачности в момент съемки.
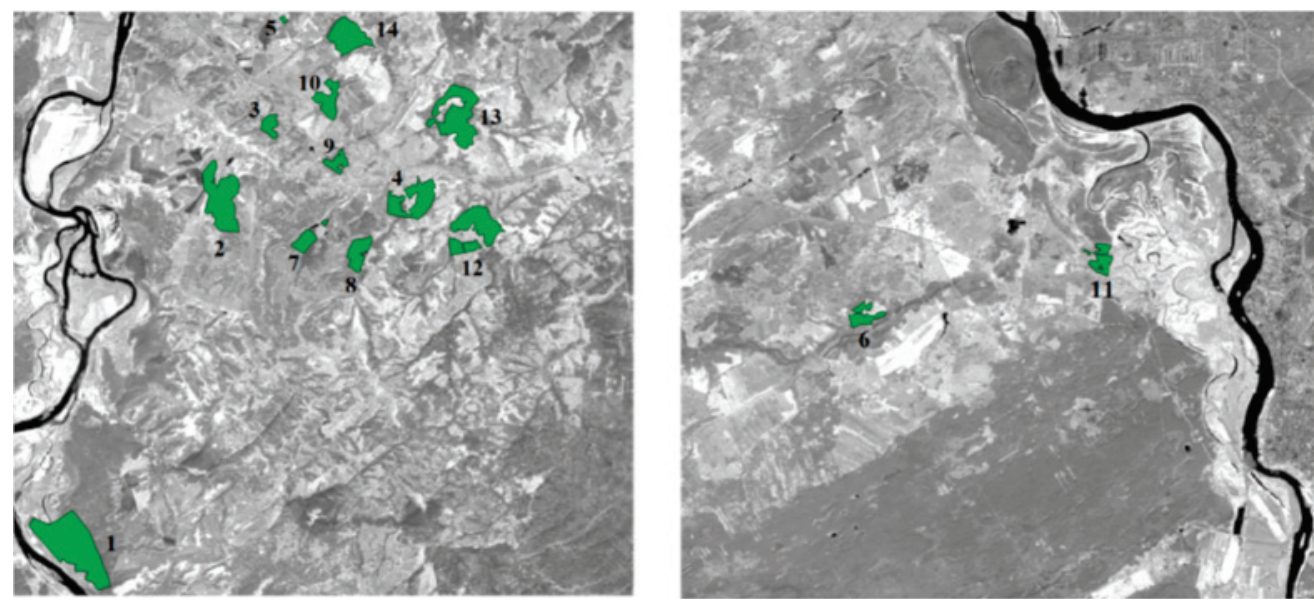

Рис. 2. Схема расположения припоселковых кедровников: 1 - Лесной парк у с. Яр, 2 - Лучаново-Ипатовский, 3 - Магадаевский, 4 - Нижне-Сеченовский, 5 - Трубачевский, 6 - Вороновский, 7 - Аксеновский, 8 - Белоусовский, 9 - Богашевский, 10 - Лоскутовский, 11 - Петровский, 12 - Петуховский, 13 - Плотниковский, 14 - Протопоповский

Fig. 2. Scheme of location of cedar forests: 1 - Forest Park near the village Yar, 2 - Luchanovo-Ipatovskiy, 3 - Magadaevskiy, 4 - NizhneSechenovskiy, 5-Trubachevskiy, 6 -Voronovskiy, 7 -Aksenovskiy, 8-Belousovskiy, 9-Bogashovskiy, 10 - Loskutovskiy, 11 - Petrovskiy, 12 - Petukhovskiy, 13 - Plotnikovskiy, 14 - Protopopovskiy 
таблииа 2. Список используемых космических снилков Table $2 . \quad$ List of used satellite images

\begin{tabular}{|c|c|c|}
\hline $\begin{array}{l}\text { Дата съемки } \\
\text { Shooting date }\end{array}$ & $\begin{array}{l}\text { Hoмep Landsat } \\
\text { Landsat Number }\end{array}$ & $\begin{array}{c}\text { Номера снимков в соответствии с } \\
\text { системой WRS2 (Path-Row) } \\
\text { Numbers of images in accordance } \\
\text { with the system WRS2 (Path-Row) }\end{array}$ \\
\hline 26.09 .2002 & 7 & \multirow{11}{*}{$148-21$} \\
\hline 28.08 .2006 & \multirow{6}{*}{5} & \\
\hline 31.08 .2007 & & \\
\hline 04.10 .2008 & & \\
\hline 07.10 .2009 & & \\
\hline 08.09 .2010 & & \\
\hline 27.09 .2011 & & \\
\hline 14.07 .2013 & \multirow{4}{*}{8} & \\
\hline 18.08 .2014 & & \\
\hline 20.07 .2015 & & \\
\hline 26.08 .2107 & & \\
\hline
\end{tabular}

Данные Landsat уровня обработки L1T поставляются в калиброванном виде, где значения пикселей каждого канала многозонального снимка представлены в виде безразмерных величин DN (Digital Number), пропорциональных интенсивности излучения, достигшего сенсора на борту спутника. Для корректного проведения исследований была проведена предварительная обработка данных, заключающаяся в радиометрической коррекции данных с использованием формул, приведенных в работах [52-55]. В результате значения DN были пересчитаны в значения отражательной способности (коэффициенты спектральной яркости) участков на поверхности Земли, покрываемых пикселем. Предварительная обработка данных и расчет значений NDVI выполнен в геоинформационной системе QGIS [56].

На следующем этапе рассчитаны средние значения NDVI внутри каждого полигона, представляющего кедровник на цифровой карте. Для этого проведен пространственный анализ данных с использованием инструмента «Зональная статистика» геоинформационной системы QGIS [56]. Алгоритм анализа данных приведен на рис. 3 .

Проведена оценка корреляции межгодовой динамики значений NDVI с метеоусловиями вегетационного периода. Для этого ряды значений NDVI, усредненные для каждого вегетационного периода, сопоставлены с рядами усредненных температур и осадков за апрель-сентябрь каждого года по метеоданным, полученным с сайта «Погода и климат» [57]. Проведен расчет коэффициентов корреляций между показателями NDVI и состоянием деревьев (средневзвешенной категории состояния деревьев в древостое (СКС) и индексом жизненного состояния (ИЖС)) [по 43]. Объем выборки для расчета значений NDVI составил 154 единицы; для анализа силы связи межгодовой динамики значений NDVI с метеоусловиями вегетационного периода - 462 единицы; для корреляций между показателями NDVI, CKC и ИЖС также 462 единицы. Коэффициенты корреляции между рядами рассчитаны с доверительной вероятностью $\beta=0,95$. Значения среднеквадратических отклонений находятся в пределах от 0,017 до 0,043.

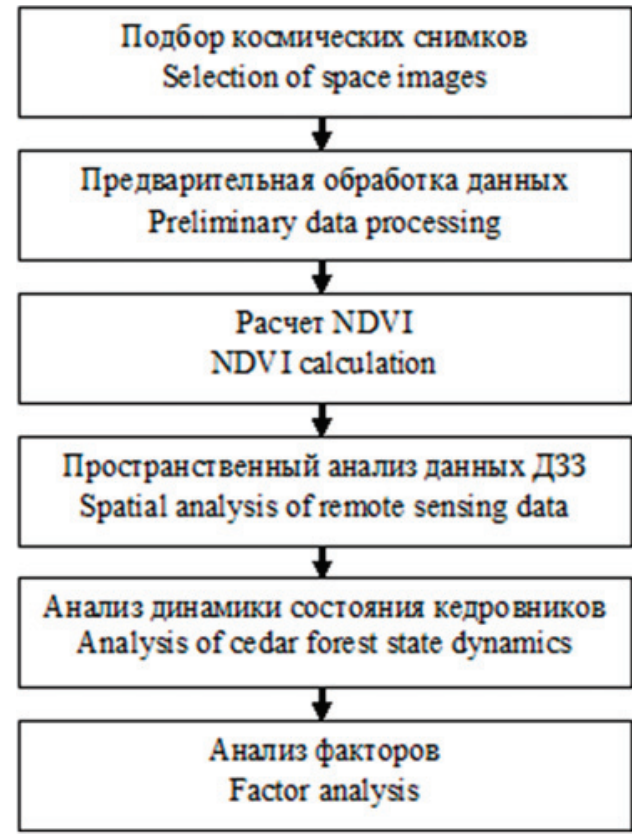

Рис. 3. Алгоритм анализа данных дистанционного зондирования Земли и данных наземных обследований для оценки состояния кедровников

Fig. 3. Algorithm of analysis of remote sensing data and ground truth data for assessment of cedar forest state

\section{Результаты}

Для анализа динамики значений NDVI с 2002 по 2017 г. данные представлены в виде графиков NDVI с нанесенными линиями трендов (рис. 4), описывающих тенденции динамики NDVI.

Тренды высокобонитетных кедровников описываются уравнениями (1) и (2):

$$
\begin{aligned}
& y=0,006 x+0,541 ; R^{2}=0,087 \\
& \text { (Богашовский кедровник), } \\
& y=0,006 x+0,506 ; R^{2}=0,051 \\
& \text { (Вороновский кедровник). }
\end{aligned}
$$

Ход графиков Аксеновского и Петровского припоселковых кедровников заметно отличается от среднегрупповых, а тренды значений их NDVI описываются уравнениями (3) и (4):

$$
\begin{gathered}
y=-0,003 x+0,502 ; R^{2}=0,015 \\
\text { (Аксеновский кедровник), } \\
y=-0,001 x+0,555 ; R^{2}=0,002 \\
\text { (Петровский кедровник). }
\end{gathered}
$$

Скорость роста значений NDVI кедровников в период с 2002 по 2017 г. составляет 6 у.е., Аксеновского - 3 у.е., причем в период с 2002 по 2015 г. значения его NDVI в 80 \% наблюдений минимальны. Поскольку значения экстремумов графика характеризуют плотность и состояние лесных массивов, то по данным ДЗ3 самым ослабленным являлся Аксеновский кедровник, что было подтверждено данными наземных обследований. В 2011 г. произошло повреждение его лесных насаждений короедом шестизубчатым на площади 11,6 га. В 2013 г. вредитель распространился еще 


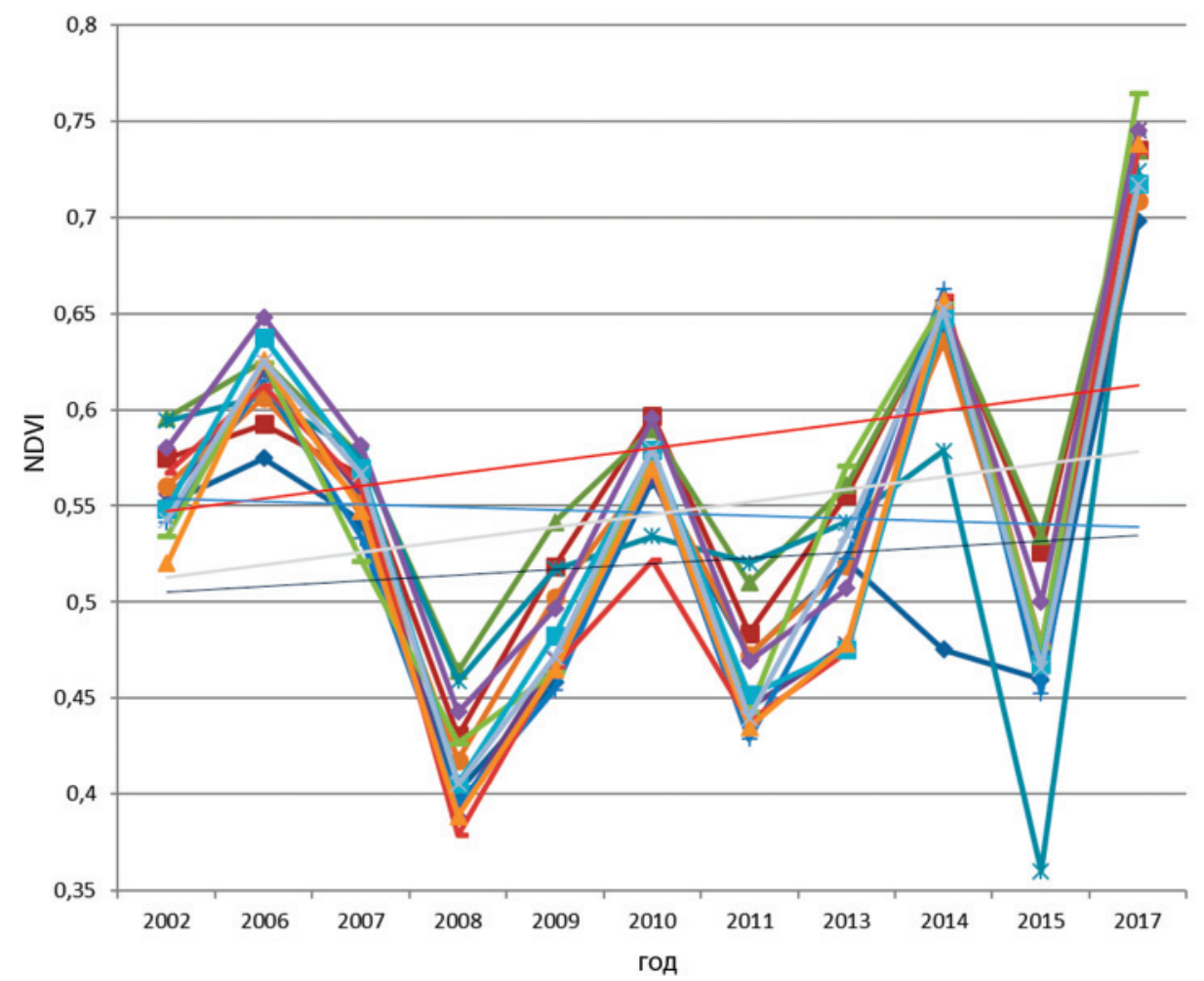

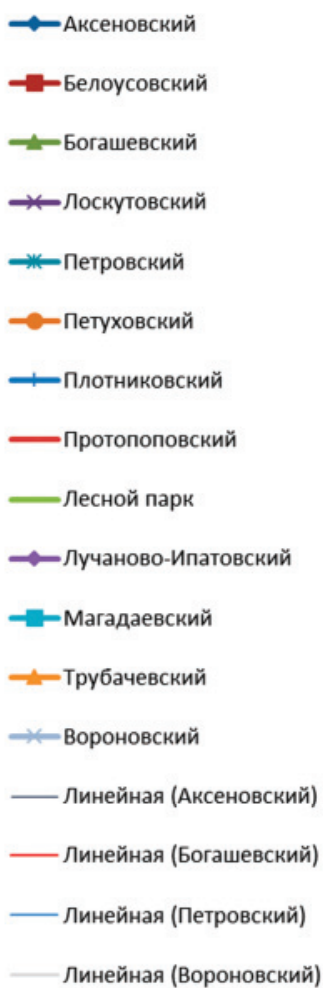

Pис. 4. Изменение значений NDVI припоселковых кедровников в 2002-2017 г2.

Fig. 4. Changes in NDVI values of cedar forests in 2002-2017

на 3 га. В 2014 г. площадь, охваченная вредителем, составила 67,5 га, т. е. $69 \%$ всей площади кедровника. Изменения состояния Аксеновского кедровника нашли отражение в падении значений NDVI. Для предотвращения деградации кедровника в 2015 г. на площади 67,5 га были проведены санитарные рубки. В результате формирования новой поросли состояние лесного массива улучшилось, соответственно, произошел резкий рост значений NDVI и его выравнивание со среднегрупповым значением.

В отличие от Аксеновского, Петровский кедровник в период с 2002 по 2012 г. характеризовался более высокими значениями NDVI, что свидетельствует о его изначально хорошем состоянии. В кедровнике производили подсадку молодых деревьев и осуществляли необходимый уход, благодаря чему он достиг максимального из всех изученных кедровников индекса жизненного состояния (более чем в 2 раза выше, чем у Аксеновского) и минимального показателя поврежденности. В 2014 г. значения NDVI резко упали вследствие начала дачного строительства в марте 2013 г. Также в 2014 г. в результате весеннего урагана произошел вывал леса на площади 8,5 га (8,4 \% площади кедровника). Более 170 деревьев было повалено с отрывом от почвы всей корневой системы. Летом того же года на площади 0,4 га был зафиксирован очаг заражения короедом шестизубчатым. Следовательно, изначально здоровый Петровский кедровник оказался ослабленным в ре- зультате негативных антропогенных и природных воздействий (вырубка, ветровал, повреждение энтомовредителями).

Низкие значения NDVI зафиксированы также для Протопоповского кедровника, поврежденного пожарами, ветровалами и энтомовредителями. Кроме того, его территория, как и территория Аксеновского кедровника, была пройдена санитарными рубками, а значительная часть полностью вырублена для предотвращения возрастной деградации. Это также нашло отражение в снижении значений их NDVI. Таким образом, проведенный ретроспективный анализ ДЗ3 позволил дать количественную оценку динамики состояния припоселковых кедровников, а наземные обследования - определить причины его изменения.

Установлено, что коэффициенты корреляции между рядами средних значений NDVI отдельных кедровников и соответствующими рядами средних гидротермических показателей недостоверны. Это свидетельствует о независимости процессов вегетации изученных кедровников от температуры воздуха и количества осадков и высоких адаптационных возможностях кедровников. Только для Аксеновского кедровника, характеризуемого как "сильно ослабленный», показана отрицательная корреляция средней силы между значениями NDVI и температурой воздуха. Следовательно, высокие температуры воздуха и засуха усиливали стресс и приводили к снижению уровня жизнедеятельности наиболее уязвимых деревьев и всей по- 
пуляции в целом. Для здоровых кедров подобные нагрузки находились в пределах нормы реакции.

Для интегральной количественной индикации состояния древостоя наряду со значениями NDVI были использованы показатели ИЖС и СКС. Установлена достоверная средняя связь между показателями NDVI и CKC деревьев в древостое $(+0,630)$ и высокая связь между NDVI и ИЖС древостоя $(+0,790)$. Теснота наблюдаемой связи между значениями NDVI свидетельствует о корректности оценки жизнеспособности по данным ДЗ3. СКС деревьев в древостое характеризует каждую категорию деревьев (здоровые, ослабленные и т. д.) с помощью суммы квадратов площадей поперечного сечения на высоте ствола 1,3 м [43]. ИЖС древостоя отражает объемы древесины каждой категории деревьев («здоровое», «ослабленное», «сильно ослабленное» «полностью разрушенное»). Он более прост, но менее точен, чем СКС (расчет по запасу), поскольку не учитывает деревья высотой до 1,3 м, а также деревья разных размеров. Этим объяснимы различия коэффициентов корреляций между СКС деревьев, ИЖС древостоя и NDVI. Установленные взаимосвязи позволяют использовать значения NDVI для предварительной оценки интегрального индикатора текущего состояния кедровников.

\section{Выводы}

1. Применение данных ДЗ3 позволяет ранжировать припоселковые кедровники Томской области по их состоянию. В период с 2002 по 2017 г.

\section{СПИСОК ЛИТЕРАТУРЫ}

1. US Forest Service. URL: https://www.fs.fed.us (дата обращения: 20.02.2018).

2. Green Policy360-eOS. URL: http://www.greenpolicy360.net (дата обращения: 20.02.2018).

3. Полищук Ю.М., Хамедов В.А., Русакова В.В. Дистанционные исследования воздействия факельного сжигания попутного газа на лесорастительный покров нефтедобывающей территории с использованием вегетационного индекса // Современные проблемы дистанционного зондирования Земли из космоса. 2016. - T. 13. - № 1. - C. 61-69.

4. Dynamic Signaling of changes to forests using exponentially weighted moving average charts / E.B. Brooks, Y. Zhiqiang, A. Valerie, H. Randolph, T.Wynne // Forests. - 2017. - V. 8. № 9. - P. 304-325.

5. Курганович К.А., Макаров В.П. Использование вегетационных индексов NDVI для оценки влияния пожаров на динамику растительности Цасучейского бора / Вестник ЗабГУ. - 2015. № 02 (117). - C. 27-36.

6. Kovalev A., Tokareva 0. Using MODIS NDVI products for vegetation state monitoring on the oil production territory in Western Siberia // MATEC Web of Conferences. - 2016. - V. 48. № 05003. - P. 1-4. URL: https://doi.org/10.1051/matecconf/20164805003 (дата обращения: 20.02.2018).

7. Yashchenko I.G., Peremitina T.0. Application of the Terra MODIS satellite data for environmental monitoring in Western Siberia // International Archives of the Photogrammetry, Remote Sensing and Spatial Information Sciences - ISPRS Archives. 2016 - V. 41 - P. 185-187. максимальные значения NDVI установлены для Богашовского и Белоусовского кедровников, минимальные - для Аксеновского, Плотниковского и Протопоповского.

2. Отсутствие достоверных корреляционных связей значений NDVI с количеством осадков и суммой температур свидетельствует об устойчивости кедровников к метеоусловиям вегетационного периода. Достоверная отрицательная связь между значениями NDVI и средней температурой воздуха выявлена только для Аксеновского кедровника, характеризуемого как "сильно ослабленный» и находящегося на границе адаптационных возможностей.

3. Выявлена средняя положительная связь между показателями NDVI и CKC деревьев в древостое $(+0,630)$ и высокая средняя положительная связь между NDVI и ИЖС древостоя $(+0,790)$.

Результаты, полученные в ходе работы, могут быть использованы для мониторинга и своевременного обеспечения сохранности припоселковых кедровников.

В перспективе планируются специальные исследования по развитию и уточнению полученной информации, в частности, по идентификации доли кедровых насаждений в получаемых значениях NDVI, анализу межсезонной и междекадной динамики значений NDVI кедровников и выявлению причин, их обусловливающих.

Работа выполнена в Томском политехническом университете в ралках програмлы повышения конкурентоспособности Толского политехнического университета.

8. Сканэкс. URL: http://scanex.ru/data/satellites/ (дата обращения: 20.02.2018).

9. Above-ground biomass prediction by Sentinel-1 multitemporal data in central Italy with integration of ALOS2 and Sentinel2 data / G.V. Laurin, J. Balling, P. Corona, W. Mattioli, D. Papale, N. Puletti, M. Rizzo, J. Truckenbrodt, M. Urban // Journal of Applied Remote Sensing. - 2018. - V. 12. - № 1. - 016008. URL: http://dx.doi.org/10.1117/1.JRS.12.016008 (дата обращения: 20.02.2018).

10. Mjachina K., Hu Z., Chibilyev A. Detection of damaged areas caused by the oil extraction in a steppe region using winter Landsat imagery // Journal of Applied Remote Sensing. - 2018. V. 12 (1). - № 016017. - P. 1-14.

11. How similar are forest disturbance maps derived from different Landsat time series algorithms? / W.B. Cohen, S.P. Healey, Z. Yang, S.V. Stehman, C.K. Brewer, E.B. Brooks, N. Gorelick, C. Huang, M.J. Hughes, R.E. Kennedy, T.R. Loveland, G.G. Moisen, T.A. Schroeder, J.E. Vogelmann, C.E. Woodcock, L. Yang, Z. Zhu // Forests. - 2017. - V. 8. - № 4. - P. 98-122.

12. Polichtchouk Y., Tokareva 0. Geoinformation analysis of atmosphere pollution impact on landscape of Siberian oil-producing territories // Proceedings of SPIE. - 2001. - V. 4341. P. 571-576.

13. Марков Н.Г. Геоинформационные системы предприятий нефтегазовой отрасли: функциональность, архитектура и перспективы развития // Известия Томского политехнического университета. Инжиниринг георесурсов. - 2017. - Т. 328. - № 9. C. $16-32$.

14. Kharuk V.I., Ranson K.J., Dvinskaya M.L. Response of Pinus sibirica and Larix sibirica to climate change in southern Siberian al- 
pine forest-tundra ecotone // Scandinavian Journal of Forest Research. - 2009. - V. 24. - № 2. - P. 421-426.

15. Climate-induced mortality of Siberian pine and fir in the Lake Baikal Watershed / V.I. Kharuk, S.T. Im, I.A. Petrov, A.S. Golyukov, K.J. Ranson, M.N. Yagunov // Forest Ecology and Management. - 2017. - V. 384. - P. 191-199. URL: https://doi.org/ 10.1016/j.foreco.2016.10.050 (дата обращения: 20.02.2018).

16. Millar C.I., Stephenson N.L. Temperate forest health in an era of emerging mega disturbance // Science. - 2015. - № 21. P. $823-826$.

17. Windthrow detection in European forests with very high-resolution optical data K. / Einzmann, M. Immitzer, S. Böck, 0. Bauer, A. Schmitt, C. Atzberger // Forests. - 2017. - V. 8. - № 1. P. 21-53.

18. Remote Sensing in Forest Health Protection: FHTET Report No. 00-03 August 2000 / W.M. Ciesla. - Salt Lake City, Fort Collins: USDA Forest Service, Remote Sensing Applications Center, Forest Health Technology Enterprise Team, 2000. - 266 p. URL: https://www.fs.fed.us/foresthealth/technology/pdfs/RemoteSensingForestHealth00 03.pdf (дата обращения: 20.02.2018).

19. Ecological Foundations for Fire Management in North American Forest and Shrubland Ecosystems: General Technical Report PNW-GTR-779 March 2009 / J.E. Keeley, G.H. Aplet, N.L. Christensen, S.G. Conard, E.A. Johnson, P.N. Omi, D.L. Peterson, T.W. Swetnam. - Portland: USDA Forest Service, Pacific Northwest Research Center, 2009. - 100 p. URL: https://www.fs.fed.us/pnw/pubs/pnw_gtr779.pdf (дата обращения: 20.02.2018).

20. Chu T., Guo X., Takeda K. Effects of burn severity and environmental conditions on post-fire regeneration in siberian larch forest // Forests. - 2017. - V. 8. - № 3. - P. 76-91.

21. Norman S.P., Koch F.H., Hargrove W.W. Review of broad-scale drought monitoring of forests: Toward an integrated data mining approach / Forest Ecology and Management. - 2016. - V. 380. P. $346-358$.

22. Forest cover change and illegal logging in the Ukrainian Carpathians in the transition period from 1988 to 2007 / T. Kuemmerle, 0. Chaskovskyy, J. Knorn, V.C. Radeloff, I. Kruhlov, W.S. Keeton, P. Hostert // Remote Sensing of Environment. 2009. - V. 113. - P. 1194-1207.

23. Romero-Sanchez M.E., Ponce-Hernandez R. Assessing and monitoring forest degradation in a deciduous tropical forest in Mexico via remote sensing indicators // Forests. - 2017. - V. 8. - № 9. P. 302-304.

24. Using intra-annual Landsat time series for attributing forest disturbance agents in Central Europe / J. Oeser, D. Pflugmacher, C. Senf, M. Heurich, P. Hostert // Forests. - 2017. - V. 8. № 7. - P. 25-46.

25. Assessment of Forest Degradation in Vietnam Using Landsat Time Series Data / J.E. Vogelmann, P.V. Khoa, D.X. Lan, J. Shermeyer, H. Shi, M.C. Wimberly, H.T. Duong, L.V. Huong // Forests. - 2017. - V. 8. - № 7 (7). - P. 238-258.

26. The State of Canada's Forests. Annual Report / K. Einzmann, M. Immitzer, S. Böck, 0. Bauer, A. Schmitt, C. Atzberger. - Ottawa: Canadian Forest Service, 2017. - 92 p.

27. Hedwall P.0., Mikusiński G. Structural changes in protected forests in Sweden: implications for conservation functionality // Canadian Journal of Forest Research. - 2015. - V. 45. - № 9. P. 1215-1224.

28. Pasko 0.A., Baranova A.V. Forest fire situation analysis over forest reserve land in Tomsk petroleum province // IOP Conference Series: Earth and Environmental Science. - 2015. - V. 24 (1). URL: http://dx.doi.org/10.1088/1755-1315/27/1/012040 (дата обращения: 20.02.2018).

29. Chu T., Guo X., Takeda K. Effects of burn severity and environmental conditions on post-fire regeneration in siberian larch forest // Forests. - 2017. - V. 8. - № 3. - P. 76-83.
30. Post-fire forest dynamics and climate variability affect spatial and temporal properties of spruce beetle outbreaks on a Sky Island mountain range / C.D. O'Connor, A.M. Lynch, D.A. Falk, T.W. Swetnam // Forest Ecology and Management. - 2015. V. 336. - P. 148-162.

31. Prediction of forest canopy and surface fuels from lidar and satellite time series data in a bark beetle-affected forest / B.C. Bright, A. Hudak, H. Meddens, T.J. Hawbaker, J.S. Briggs, R.E. Kennedy // Forests. - 2017. - V. 8. - № 9. - P. 322-345.

32. Lidar and multispectral imagery classifications of balsam fir tree status for accurate predictions of merchantable volume / S. Y0ga, J. Bégin, S. Benoit, D. Gatziolis // Forests. - 2017. - V. 8. № 7. - P. 253-273.

33. Observed and anticipated impacts of drought on forests insects and diseases in the United States / T.E. Kolb, C.J. Fettig, M.P. Ayres, B.J. Bentz, J.A. Hicke, R. Mathiasen, J.E. Stewart, A.S. Weed // Forest Ecology and Management. - 2016. - V. 380. P. 321-334. URL: http://dx.doi.org/10.1016/j.foreco.2016.04.051 (дата обращения: 20.02.2018).

34. Attribution of disturbance agents to forest change using a Landsat time series in tropical seasonal forests in the Bago Mountains, Myanmar / K. Shimizu, O.S. Ahmed, R. Ponce-Hernandez, T. Ota, Z.C. Win, N. Mizoue, S. Yoshida // Forests. - 2017. V. 8. - № 6. - P. 218-236.

35. Kovyazin V., Romanchikov A., Pasko 0. Comparative analysis of forest lands cadastral appraisal estimated with regards to wood and food resources // IOP Conference Series: Earth and Environmental Science. - 2015. - V. 27 (1). URL: http://iopscience.iop.org/article/10.1088/1755-1315/27/1/012039/meta (дата обращения: 20.02.2018).

36. Taxation indices of forest stand as the basis for cadastral valuation of forestlands / V. Kovyazin, V. Belyaev, 0. Pasko, A. Romanchikov // IOP Conference Series: Earth and Environmental Science. - 2014. V. 21 (1). URL: http://iopscience.iop.org/article/10.1088/ 1755-1315/21/1/012026 (дата обращения: 20.02.2018).

37. Данчева А.В., Залесов С.В. Использование комплексного оценочного показателя при оценке состояния сосняков государственного лесного природного резервата «Семей Орманы» // Известия С.-Пб ЛТА. - 2016. - № 215. - С. 41-54.

38. «Развитие лесного хозяйства на 2013-2020 годы» (с изменениями на 30 марта 2018 года). Правительство РФ. Постановление от 15 апреля 2014 года N 318. URL: http://base.garant.ru/70644228/ (дата обращения: 20.09.2018).

39. Хвойные породы мира. URL: http://www.bizzcom.ru/whvoy/ index.htm (дата обращения: 20.02.2018).

40. Бабич Н.А., Хамитов Р.С., Хамитова С.М. Селекция и семенная репродукция кедра сибирского. - Вологда; Молочное: ВГМХА, 2014. - $154 \mathrm{c}$.

41. Rogachev A.D., Salakhutdinov N.F. Chemical composition of Pinussibirica (Pinaceae) // Chemistry \& Biodiversity. - 2015. V. 12. - № 1. - P. 1-53.

42. Дебков Н.М. Припоселковые кедровники юга Западно-Сибирской равнины: история и современное состояние, рекомендации по устойчивому управлению. - М.: Всемирный фонд дикой природы (WWF), 2014. - 52 с.

43. Бисирова Э.М., Кривец С.А. Комплексная характеристика состояния древостоев кедра сибирского в припоселковых кедровниках - памятниках природы Томской области // Интерэкспо Гео-Сибирь. - 2010. URL: https://cyberleninka.ru/article/n/kompleksnaya-harakteristika-sostoyaniya-drevostoev-kedra-sibirskogo-v-priposelkovyh-kedrovnikah-pamyatnikah-prirody-tomskoy-oblasti (дата обращения: 20.02.2018).

44. Припоселковые кедровники и их социальное значение. URL: www.activestudy.info/priposelkovye-kedrovniki-i-ix-socialnoeznachenie (дата обращения: 20.02.2018).

45. Бех И.А., Кривец С.Л., Бисирова Э.М. Кедр - жемчужина Сибири. - Томск: Изд-во «Печатная мануфактура», 2009. - 50 с. 
46. Токарева О.С., Полищук Ю.М. Использование космических снимков для экологической оценки воздействия факельного сжигания попутного газа на нефтяных месторождениях Сибири // Оптика атмосферы и океана. - 2014. - Т. 27. - № 7. - С. 647-651.

47. Атлас особо охраняемых природных территорий Томской области. - Томск: Литературное бюро, 2017. - 134 с.

48. Erdas Imagine. URL: https://innoter.com/software/erdas-imagine/ (дата обращения: 20.02.2018).

49. Monitoring Vegetation Systems in the Great Plains with ERTS / J.W. Rouse, R.H. Haas, J.A. Scheel, D.W. Deering $/ / 3^{\text {rd }}$ Earth Resource Technology Satellite (ERTS) Symposium: Proc. Conf. USA, Washington, 1973. - V. 1. - P. 309-317. URL: https:// ntrs.nasa.gov/archive/nasa/casi.ntrs.nasa.gov/ 19740022592.pdf (дата обращения 20.02.2018).

50. Pasquarella V.J., Bradley B.A., Woodcock C.E. Near-Real-Time Monitoring of insect defoliation using Landsat time series // F0rests. - 2017. - V. 8. - № 8. - P. 275-295.

51. USGS Earth Explorer. URL: https://earthexplorer.usgs.gov (дата обращения: 20.02.2018).
52. LANDSAT 8 (L8) Data users handbook. URL: https://landsat.usgs.gov/sites/default/files/documents/Landsat8DataUsersHandbook.pdf (дата обращения: 20.02.2018)

53. Revised Landsat-5 TM radiometric calibration procedures and postcalibration dynamic ranges // IEEE Transactions on geoscience and remote sensing. - 2003. - V. 41. - № 11. P. 2674-2677.

54. Landsat 7 Science Data Users Handbook. URL: https:/landsat.gsfc.nasa.gov/wpcontent/uploads/2016/08/Landsat7_Handbook.pdf (дата обращения: 20.02.2018).

55. Коррекция материалов Landsat. URL: http:/gislab.info/qa/ landsat-data-correction.html (дата обращения: 20.02.2018).

56. QGIS-1.6. URL: https://www.qgis.org/ru/site (дата обращения: 20.02.2018).

57. Погода и климат. URL: http://pogodaiklimat.ru (дата обращения: 20.02.2018).

Поступила 10.11.2018 г.

\section{Информация об авторах}

Пасько О.A., доктор сельскохозяйственных наук, профессор отделения геологии Инженерной школы природных ресурсов Национального исследовательского Томского политехнического университета.

Tокарева O.C., кандидат технических наук, доцент отделения информационных технологий Инженерной школы информационных технологий и робототехники Национального исследовательского Томского политехнического университета.

Алшаиби А.Д.А., студент отделения информационных технологий Инженерной школы информационных технологий и робототехники Национального исследовательского Томского политехнического университета; преподаватель Главного управления образования Диялы.

Черникова T.Ю., аспирант отделения геологии Инженерной школы природных ресурсов Национального исследовательского Томского политехнического университета.

Кабраль П., доктор прикладной математики, доцент Школы информационного менеджмента Лиссабонского университета. 


\section{ASSESSMENT OF STATE OF CEDAR FORESTS IN TOMSK REGION USING REMOTE SENSING DATA OF THE EARTH}

Olga A. Pasko',

oap@tpu.ru

Olga S. Tokareva',

ost@tpu.ru

Ahmed J. A. Alshaibi ${ }^{12}$,

ahmedalshaiby88@gmail.com

\section{Tatyana Yu. Chernikova',}

chernikova@green.tsu.ru

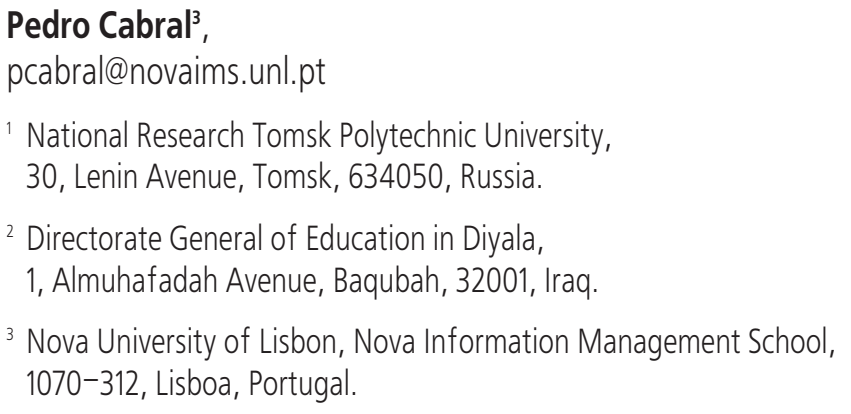

The relevance of the research is caused by the necessity to obtain objective information on the condition of forests for their protection from fires, diseases and pests, as well as for forestry and logging production.

The aim of the research is the quantitative and qualitative assessment of changes in the condition of cedar forests on the example of the Tomsk region using ground survey methods and Earth remote sensing data.

The objects of the research are the 13 cedar forests located on forest lands and belonging to the forestry branch of institution "Tomsk forest management» in Tomsk region.

Methods: thematic mapping of the territory; calculation of the indicator of the number of photosynthetically active biomass NDVI (Normalize Difference Vegetation Index) on space images of medium spatial resolution (30 m) from the satellites Landsat 5 (camera TM), 7 (camera ETM+) and 8 (camera OLI), obtained in the period from 2002 to 2015 from the archive of the US Geological Survey using the Internet service Earth Explorer; spatial analysis of data using geographic information technologies; statistical processing of the obtained results by correlation and regression analysis.

Result. A comprehensive assessment of 13 cedar forests was given; the dynamics of NDVI values in the period from 2002 to 2017 was analyzed; the main reason (illegal logging, windfalls, fires and spread of pests) were determined; the cedar forests were grouped according to their status; the maximum values of NDVI were set for the Bogashovskiy and Belousovskiy cedar forests, the minimum values of NDVI were set for Aksenovskiy, Protopopovskiy, Plotnikovskiy cedar forests; positive correlations between NDVI values and tree state were shown: high correlation - with the vital index, and the average correlation - with the weighted average tree state category in the forest; reliable correlation of NDVI values of cedar trees with the amount of precipitation and the amount of temperatures have not been found (except for the Aksenovskiy cedar forest, characterized as "severely weakened»); the proposed approaches are applicable to the evaluation of any cedar forests.

Key words:

Cedar forests, monitoring, state, assessment, ground survey, remote sensing data, NDVI.

The research is carried out at Tomsk Polytechnic University within the framework of Tomsk Polytechnic University Competitiveness Enhancement Program.

\section{REFERENCES}

1. US Forest Service. Available at: https://www.fs.fed.us (accessed 20 February 2018).

2. Green Policy360-eOS. Available at: http://www.greenpolicy360.net (accessed 20 February 2018).

3. Polishchuk Yu.M., Khamedov V.A., Rusakova V.V. Remote studies of gas flaring impact on forest cover in oil-producing areas using vegetation index. Sovremennye Problemy Distantsionnogo Zondirovaniya Zemli iz Kosmosa, 2013, vol. 13, no. 1, pp. 61-69. In Rus.
4. Brooks E.B., Zhiqiang Y., Valerie A., Randolph H., Wynne T. Dynamic Signaling of changes to forests using exponentially weighted moving average charts. Forests, 2017, vol. 8, no. 9, pp. 304-325.

5. Kurganovich K.A., Makarov V.P. Ispolzovanie vegetatsionnykh indeksov NDVI dlya otsenki vliyaniya pozharov na dinamiku rastitelnosti Tsasucheiskogo bora [Using of vegetation indices NDVI for estimation of influence of fires on dynamics of vegetation of Tsasucheysky boron]. Vestnik ZabGU, 2015, no. 02 (117), pp. 27-36. 
6. Kovalev A., Tokareva 0. Using MODIS NDVI products for vegetation state monitoring on the oil production territory in Western Siberia. MATEC Web of Conferences, 2016, vol. 48, no. 05003, pp. 1-4. Available at: https://doi.org/10.1051/matecconf/20164805003 (accessed 20 February 2018).

7. Yashchenko I.G., Peremitina T.0. Application of the Terra MODIS satellite data for environmental monitoring in Western Siberia. International Archives of the Photogrammetry, Remote Sensing and Spatial Information Sciences - ISPRS Archives, 2016, vol. 41, pp. 185-187.

8. Scanex. Available at: http://scanex.ru/data/satellites/ (accessed 20 February 2018).

9. Laurin G.V. Balling J., Corona P., Mattioli W., Papale D., Puletti N., Rizzo M., Truckenbrodt J., Urban M. Above-ground biomass prediction by Sentinel-1 multitemporal data in central Italy with integration of ALOS2 and Sentinel-2 data. Journal of Applied Remote Sensing, 2018, vol. 12, no. 1, 016008. Available at: http://dx.doi.org/10.1117/1.JRS.12.016008 (accessed 20 February 2018).

10. Mjachina K., Hu Z., Chibilyev A. Detection of damaged areas caused by the oil extraction in a steppe region using winter Landsat imagery. Journal of Applied Remote Sensing, 2018, vol. 12 (1), no. 016017, pp. 1-14.

11. Cohen W.B., Healey S.P., Yang Z., Stehman S.V., Brewer C.K., Brooks E.B., Gorelick N., Huang C., Hughes M.J., Kennedy R.E., Loveland T.R., Moisen G.G, Schroeder T.A., Vogelmann J.E., Woodcock C.E., Yang L., Zhu Z. How similar are forest disturbance maps derived from different Landsat time series algorithms? Forests, 2017, vol. 8, no. 4, pp. 98-122.

12. Polichtchouk Y., Tokareva 0. Geoinformation analysis of atmosphere pollution impact on landscape of Siberian oil-producing territories. Proceedings of SPIE, 2001, vol. 4341, pp. 571-576.

13. Markov N.G. Geoinformation systems for oil and gas enterprises: functionality, architecture and development prospects. Bulletin of the Tomsk Polytechnic University. Geo Assets Engineering, 2017, vol. 328, no. 9, pp. 16-32. In Rus.

14. Kharuk V.I., Ranson K.J., Dvinskaya M.L. Response of Pinus sibirica and Larix sibirica to climate change in southern Siberian alpine forest-tundra ecotone. Scandinavian Journal of Forest Research, 2009, vol. 24, no. 2, pp. 421-426.

15. Kharuk I.V., Im S.T., Petrov I.A., Golyukov A.S., Ranson K.J., Yagunov M.N. Climate-induced mortality of Siberian pine and fir in the Lake Baikal Watershed. Forest Ecology and Management, 2017, vol. 384, pp. 191-199. Available at: https://doi.org/ 10.1016/j.foreco.2016.10.050 (accessed 20 February 2018).

16. Millar C.I., Stephenson N.L. Temperate forest health in an era of emerging mega disturbance. Science, 2015, no. 21, pp. 823-826.

17. Einzmann K., Immitzer M., Böck S., Bauer 0., Schmitt A., Atzberger C. Windthrow detection in European forests with very high-resolution optical data. Forests, 2017, vol. 8, no. 1, pp. 21-53.

18. Ciesla W.M. Remote Sensing in Forest Health Protection: FHTET Report No.00-03 August 2000. Salt Lake City, Fort Collins, USDA Forest Service, Remote Sensing Applications Center, Forest Health Technology Enterprise Team, 2000. 266 p. Available at: https://www.fs.fed.us/foresthealth/technology/pdfs/ RemoteSensingForestHealth00_03.pdf (accessed 20 February 2018).

19. Keeley J.E., Aplet G.H., Christensen N.L., Conard S.G., Johnson E.A., Omi P.N., Peterson D.L., Swetnam T.W. Ecological Foundations for Fire Management in North American Forest and Shrubland Ecosystems: General Technical Report PNW-GTR779 March 2009. Portland, USDA Forest Service, Pacific Northwest Research Center, 2009. 100 p. Available at: https://www.fs.fed.us/pnw/pubs/pnw_gtr779.pdf (accessed 20 February 2018)
20. Chu T., Guo X., Takeda K. Effects of burn severity and environmental conditions on post-fire regeneration in Siberian larch forest. Forests, 2017, vol. 8, no. 3, pp. 76-91.

21. Norman S.P., Koch F.H., Hargrove W.W. Review of broad-scale drought monitoring of forests: Toward an integrated data mining approach. Forest Ecology and Management, 2016, vol. 380, pp. $346-358$.

22. Kuemmerle T., Chaskovskyy 0., Knorn J., Radeloff V.C., Kruhlov I., Keeton W.S., Hostert P. Forest cover change and illegal logging in the Ukrainian Carpathians in the transition period from 1988 to 2007. Remote Sensing of Environment, 2009, vol. 113, pp. 1194-1207.

23. Romero-Sanchez M.E., Ponce-Hernandez R. Assessing and monitoring forest degradation in a deciduous tropical forest in Mexico via remote sensing indicators. Forests, 2017, vol. 8, no. 9, pp. 302-304.

24. Oeser J., Pflugmacher D., Senf C., Heurich M., Hostert P. Using intra-annual Landsat time series for attributing forest disturbance agents in Central Europe. Forests, 2017, vol. 8, no. 7, pp. 25-46.

25. Vogelmann J.E., Khoa P.V., Lan D.X., Shermeyer J., Shi H., Wimberly M.C., Duong H.T., Huong L.V. Assessment of Forest Degradation in Vietnam Using Landsat Time Series Data. Forests, 2017, vol. 8, no. 7 (7), pp. 238-258.

26. Einzmann K., Immitzer M., Böck S., Bauer 0., Schmitt A., Atzberger C. The State of Canada's Forests. Annual Report. Ottawa, Canadian Forest Service, 2017.92 p.

27. Hedwall P.0., Mikusiński G. Structural changes in protected forests in Sweden: implications for conservation functionality. Canadian Journal of Forest Research, 2015, vol. 45, no. 9, pp. $1215-1224$

28. Pasko 0.A., Baranova A.V. Forest fire situation analysis over forest reserve land in Tomsk petroleum province. IOP Conference Series: Earth and Environmental Science, 2015, vol. 24 (1). Available at: http://dx.doi.org/10.1088/1755-1315/27/1/012040 (accessed 20 February 2018).

29. Chu T., Guo X., Takeda K. Effects of burn severity and environmental conditions on post-fire regeneration in Siberian larch forest. Forests, 2017, vol. 8, no. 3, pp. 76-83.

30. O'Connor C.D., Lynch A.M., Falk D.A., Swetnam T.W. Post-fire forest dynamics and climate variability affect spatial and temporal properties of spruce beetle outbreaks on a Sky Island mountain range. Forest Ecology and Management, 2015, vol. 336, pp. 148-162.

31. Bright B.C., Hudak A., Meddens H., Hawbaker T.J., Briggs J.S., Kennedy R.E. Prediction of forest canopy and surface fuels from lidar and satellite time series data in a bark beetle-affected forest. Forests, 2017, vol. 8, no. 9, pp. 322-345.

32. Yoga S., Bégin J., Benoit S., Gatziolis D. Lidar and multispectral imagery classifications of balsam fir tree status for accurate predictions of merchantable volume. Forests, 2017, vol. 8, no. 7, pp. $253-273$.

33. Kolb T.E., Fettig C.J., Ayres M.P., Bentz B.J., Hicke J.A., Mathiasen R., Stewart J.E., Weed A.S. Observed and anticipated impacts of drought on forests insects and diseases in the United States. Forest Ecology and Management, 2016, vol. 380, pp. 321-334. Available at: http://dx.doi.org/10.1016/j.foreco.2016.04.051 (accessed 20 February 2018).

34. Shimizu K., Ahmed 0.S., Ponce-Hernandez R., Ota T., Win Z.C., Mizoue N., Yoshida S. Attribution of disturbance agents to forest change using a Landsat time series in tropical seasonal forests in the Bago Mountains, Myanmar. Forests, 2017, vol. 8, no. 6, pp. 218-236.

35. Kovyazin V., Romanchikov A., Pasko 0. Comparative analysis of forest lands cadastral appraisal estimated with regards to wood and food resources. IOP Conference Series: Earth and Environ- 
mental Science, 2015, vol. 27 (1). Available at: http://iopscience.iop.org/article/10.1088/1755-1315/27/1/012039/meta (accessed 20 February 2018).

36. Kovyazin V., Belyaev V., Pasko 0., Romanchikov A. Taxation indices of forest stand as the basis for cadastral valuation of forestlands. IOP Conference Series: Earth and Environmental Science, 2014, vol. 21 (1). Available at: http://iopscience.iop.org/article/10.1088/1755-1315/21/1/012026 (accessed 20 February 2018).

37. Dancheva A.V., Zalesov S.V. The use of comprehensive evaluation index for assessing the condition of pine stands the State $\mathrm{F}_{0}$ rest Natural Reserve "Semey Ormany». Izvestiya S.Pb LTA, 2016, no. 215, pp. 41-54. In Rus.

38. Razvitie lesnogo khozyaistva na 2013-2020 gody (s izmeneniyami na 30 marta 2018 goda). Pravitelstuo RF. Postanovlenie ot 15 aprelya 2014 goda $N 318$ [Development of forestry for 2013-2020 (with changes as of March 30, 2018). Government of the Russian Federation. Decision of April 15, 2014, no. 318]. Available at: http://base.garant.ru/70644228/ (accessed $20 \mathrm{Se}$ ptember 2018).

39. Khvoynye porody mira [Conifers of the world]. Available at: http://www.bizzcom.ru/whvoy/index.htm (accessed 20 February 2018).

40. Babich N.A., Khamitov R.S., Khamitova S.M. Selektsiya i semennaya reproduktsiya kedra sibirskogo [Selection and seed reproduction of Siberian cedar]. Vologda; Molochnoe, VGMKhA Publ., $2014.154 \mathrm{p}$.

41. Rogachev A.D., Salakhutdinov N.F. Chemical composition of Pinussibirica (Pinaceae). Chemistry \& Biodiversity, 2015, vol. 12, no. 1, pp. 1-53.

42. Debkov N.M. Priposelkovye kedrouniki yuga Zapadno-Sibirskoi ravniny: istoriya i souremennoe sostoyanie, rekomendatsii po ustoychivomu upravleniyu [Cedar forests of neighborhood of villages of the South of West-Siberian Plain: history and current state, recommendations for sustainable management]. Moscow, World Wildlife Fund (WWF), 2014. $52 \mathrm{p}$.

43. Bisirova E.M., Krivets S.A. Kompleksnaya kharakteristika sostoyaniya drevostoev kedra sibirskogo v priposelkovykh kedrovnikakh - pamyatnikakh prirody Tomskoy oblasti [The complex characteristic of state of Siberian stone pine forests near settlements -natural reserves of Tomsk oblast]. Interekspo Geo-Sibir, 2010. Available at: https://cyberleninka.ru/article/n/kompleksnayaharakteristika-sostoyaniya-drevostoev-kedra-sibirskogo-v-priposelkovyh-kedrovnikah-pamyatnikah-prirody-tomskoy-oblasti (accessed 20 February 2018).
44. Priposelkovye kedrouniki i ikh sotsialnoe znachenie [Cedar forests of neighborhood of villages and their social significance]. Available at: www.activestudy.info/priposelkovye-kedrovniki-i-ix-socialnoe-znachenie (accessed 20 February 2018).

45. Bekh I.A., Krivets S.L., Bisirova E.M. Kedr - zhemchuzhina Sibi$r i$ [Cedar is the pearl of Siberia]. Tomsk, Pechatnaya manufaktura Publ., 2009. 50 p.

46. Polishchuk Yu.M., Tokareva O.S. The use of satellite images for ecological estimate of flare firing of gas at oil fields of Siberia. Optika Atmosfery i Okeana, 2014, vol. 27, no. 07, pp. 647-651. In Rus.

47. Atlas osobo okhranyayemykh prirodnykh territoriy Tomskoy obla$s t i$ [Atlas of specially protected natural territories of the Tomsk Region]. Tomsk, Literaturnoye byuro Publ., 2017. 134 p.

48. Erdas Imagine. Available at: https://innoter.com/software/erdas-imagine/ (accessed 20 February 2018).

49. Rouse J.W., Haas R.H., Scheel J.A., Deering D.W. Monitoring Vegetation Systems in the Great Plains with ERTS. $3^{\text {rd }}$ Earth Resource Technology Satellite (ERTS) Symposium. Proc. Conf. USA, Washington, 1973. Vol. 1, pp. 309-317. Available at: https:// ntrs.nasa.gov/archive/nasa/casi.ntrs.nasa.gov/19740022592. pdf (accessed 20 February 2018).

50. Pasquarella V.J., Bradley B.A., Woodcock C.E. Near-Real-Time Monitoring of insect defoliation using Landsat time series. $\mathrm{Fo}_{0}$ rests, 2017, vol. 8, no. 8, pp. 275-295.

51. USGS Earth Explorer. Available at: https://earthexplorer.usgs.gov (accessed 20 February 2018).

52. LANDSAT 8 (L8) Data users handbook. Available at: https://landsat.usgs.gov/sites/default/files/documents/Landsat8DataUsersHandbook.pdf (accessed 20 February 2018).

53. Revised Landsat-5 TM radiometric calibration procedures and postcalibration dynamic ranges. IEEE Transactions on geoscience and remote sensing, 2003, vol. 41, no. 11, pp. 2674-2677.

54. Landsat 7 Science Data Users Handbook. Available at: https://landsat.gsfc.nasa.gov/wpcontent/uploads/2016/08/ Landsat7_Handbook.pdf (accessed 20 February 2018).

55. Korrektsiya materialov Landsat [Correction of Landsat materials]. Available at: http://gislab.info/qa/landsat-data-correction.html (accessed 20 February 2018).

56. QGIS-1.6. Available at: https://www.qgis.org/ru/site (accessed 20 February 2018).

57. Pogoda $i$ klimat [Weather and Climate]. Available at: http://pogodaiklimat.ru (accessed 20 February 2018).

Received: 10 November 2018.

\section{Information about the authors}

Olga A.Pasko, Dr. Sc., professor, National Research Tomsk Polytechnic University.

Olga S. Tokareva, Cand. Sc., associate professor, National Research Tomsk Polytechnic University.

Ahmed J. A. Alshaibi, student, National Research Tomsk Polytechnic University; teacher, Directorate Jeneral of Education in Diyala.

Tatyana Yu. Chernikova, postgraduate student, National Research Tomsk Polytechnic University.

Pedro Cabral, PhD, Nova University of Lisbon. 